\title{
MÚLTIPLOS ASPECTOS DA EDUCAÇÃO BRASILEIRA: A ATUAÇÃO DO PROFESSOR UBIRATAN D'AMBROSIO
}

\author{
Rosimeire Aparecida Soares Borges* \\ Aparecida Rodrigues Silva Duarte* \\ Tânia Maria Mendonça Campos**
}

\section{Resumo}

Este artigo discute as contribuições do professor e pesquisador Ubiratan D’Ambrosio para a educação brasileira. O quadro teórico considera a impossibilidade de separar o eu pessoal do profissional. Desta forma, este trabalho passa por estágios diferentes e sucessivos de sua vida, desde sua infância até o presente. Todos os dados foram obtidos a partir de entrevistas realizadas com Ubiratan D’Ambrosio e das informaçóes recolhidas em documentos pertencentes ao seu arquivo pessoal. A construção da história de vida deste educador e pesquisador é frutífera para a compreensão das trajetórias da formação de professores e contribui para a compreensão do universo da educação.

Palavras-chave: Educação brasileira. História de vida. Formação de professores.

\section{INTRODUÇÁO}

A história de vida de D’Ambrosio é fecunda para a compreensão dos percursos de formação docente e contribui para a apropriação de diferentes processos de ensino e de aprendizagem e apreensão do cotidiano escolar. O modo de atuação de um professor tem profunda relação com sua história de vida, não sendo possível desvincular seu eu profissional do seu eu pessoal (NÓVOA, 2000).

A história de vida de Ubiratan D’Ambrosio se edifica a partir de seus depoimentos, que revelaram todo um processo identitário pelo qual passou. Pode-se dizer que sua identidade “é um lugar de lutas e conflitos, é um espaço de construção, de maneiras de ser e de estar na profissão, é um processo que necessitou de tempo, um tempo para refazer identidades, para acomodar inovações, para assimilar mudanças” (NÓVOA, 2000, p.16). Suas práticas pedagógicas estão vinculadas ao que ele é como pessoa e como profissional, pois essas práticas são "opções que cada um de nós tem de fazer como professor, as quais cruzam a nossa maneira de ser com a nossa maneira de ensinar e desvendam, na nossa maneira de ensinar, a nossa maneira de ser" (NÓVOA, 2000, p.17).

Doutora em Educação Matemática pela Universidade do Bandeirante Anhanguera (Uniban/SP). Professora do Mestrado em Educação da Universidade do Vale do Sapucaí (Univás), Pouso Alegre, MG. E-mail: rasborges3@gmail.com.

Doutora em Educação Matemática pela Pontifícia Universidade Católica de São Paulo (PUC/SP). Professora do Mestrado em Educação da Universidade do Vale do Sapucaí (Univás), Pouso Alegre, MG. E-mail: angel-bb@uol.com.br.

Doutora em Matemática pela Université Montpellier, França. Até 2015 foi coordenadora e professora do Programa de Pós-graduação em Educação Matemática da Universidade Bandeirante Anhanguera (Uniban) São Paulo, SP, Brasil. E-mail: taniammcampos@hotmail.com.

Instrumento: R. Est. Pesq. Educ., Juiz de Fora, v. 20, n. 2, jul./dez. 2018 
Ao longo de 68 anos de experiência docente, Ubiratan D’Ambrosio mantém um contínuo interesse pela renovaçáo do ensino. Para ele, ser professor é assumir os princípios presentes nas práticas educacionais e valorizar as potencialidades dos alunos. Suas práticas docentes não se vinculam exclusivamente à descoberta de potencialidades dos alunos no que tange à matemática, estendem-se aos mais variados campos do saber, confirmando seu contínuo interesse em relação à renovação do ensino.

As diferentes fases da formação do professor Ubiratan D’Ambrosio foram reveladas em expressōes francas e abertas, em entrevistas que nos concedeu e são abordadas neste estudo. A discrição e modéstia em sua fala poderiam levar a uma falsa e injusta avaliação de sua grande contribuição para a história da Educação Matemática no Brasil. Suas experiências do passado foram sendo evocadas aos poucos, em uma busca incansável junto aos poróes do subconsciente, de modo a se tornarem lembranças e provocar em si um repensar de suas ações e a reconstrução de sua história de vida (FREITAS, 2002).

Os caminhos do professor Ubiratan D’Ambrosio são os caminhos da pesquisa inovadora na área da Educação Matemática. Sua trajetória de vida reflete os momentos vividos com sua família, amigos, alunos, colegas de escola e trabalho, mescla registros de sua vida profissional e, por vezes, a particular. Revela ser impossível dissociar as diversas experiências: pessoal, familiar, social e profissional, da sua formação docente.

\section{Ubiratan D'Ambrosio e a escola ELEMENTAR}

Ubiratan D'Ambrosio, nas entrevistas que concedeu sobre sua formação, mencionou diversos momentos de sua vida, os quais foram marcados por incertezas e sucessos, garra, coragem, inovação, emoção, alegrias e tristezas, em uma fala moderada com grande dose de saudade a cada história contada, quando o passado e o presente quase se confundiam.

D’Ambrosio iniciou sua narrativa fazendo referência à vinda de seu avô materno, Giuseppe Graciotti, da Itália para o Brasil, no final do século XIX. Graciotti casou-se com Ada Possanzine e tiveram, dentre os filhos, Albertina Graciotti, a mãe de Ubiratan. Também da Itália para o Brasil veio seu avô paterno, Thomas D'Ambrosio, que se casou com Adelaide e teve dois filhos, dentre os quais Nicolau D'Ambrosio, o pai de Ubiratan. Albertina Graciotti e Nicolau D’Ambrosio casaram-se e, no ano de 1932, nasceu Ubiratan D’Ambrosio, o primeiro filho desse casal.

A vida escolar de Ubiratan D'Ambrosio teve início no Colégio Dante Alighieri, no ano de 1938. Não suportando ficar longe de sua mãe, acabou por não cursar a pré-escola. No ano de 1939, cursou o primeiro ano do grupo escolar (hoje, no Brasil, segundo ano do Ensino Fundamental), no interior do estado de São Paulo, onde seu pai foi morar com a família. Não se adaptando ao interior, um ano depois, a família de Ubiratan voltou a residir na cidade de São Paulo.

Em 1940, em Sáo Paulo, com oito anos de idade, Ubiratan D'Ambrosio ingressou no segundo ano escolar (equivalente, no Brasil, ao terceiro ano do Ensino Fundamental) do Liceu Coração de Jesus, onde seu pai assumiu o cargo de professor. Ele relembrou a rigidez no controle de presença desse Liceu, inclusive aos domingos, quando os alunos tinham obrigatoriedade de participar da missa dominical e do catecismo.

Concluídos os quatro primeiros anos de estudo, Ubiratan D'Ambrosio continuou nesse Liceu e, em 1943, foi aprovado no exame de admissão para ingresso no curso ginasial (corresponde atualmente, no Brasil, do sexto ao nono ano do Ensino Fundamental), onde concluiu o primeiro e segundo anos ginasiais (atual sexto e sétimo anos do Ensino Fundamental). O terceiro e quarto anos do ginasial (hoje, oitavo e nono anos do 
Ensino Fundamental), cursou na Escola Caetano de Campos, em São Paulo. Em 1946, Ubiratan D’Ambrosio ingressou no curso científico (corresponde atualmente, no Brasil, ao Ensino Médio) no Colégio Visconde de Porto Seguro, em São Paulo.

Dos professores que teve no curso científico, Ubiratan D'Ambrosio recordou-se de Abrão Bloch, que foi seu professor de Matemática e de Física nos três anos desse curso; e de Lineu de Camargo Schutzer, que ministrou Filosofia. Ele relembrou que Schutzer levava os alunos ao teatro e, segundo palavras de Ubiratan, exerceu influência em sua vida:

[...] grande parte do que eu faço também é inspirado por esse professor [...] a gente ia ao teatro e na aula comentava o que havia assistido no teatro. O teatro grego é um teatro que acaba tendo um contexto psicanalítico muito forte, então o nosso trabalho de psicanálise foi muito importante, a filosofia focalizando a psicanálise. Foi muito bom, muito bom para mim. Um grande curso de filosofia (depoimento oral, 2004).

Em relação às aulas de Biologia, eram aulas experimentais em laboratório ministradas pelo professor Dr. Tabor, que trazia para a sala de aula suas experiências obtidas em viagens que realizava pela Indonésia, África, Américas. Para Ubiratan, revelou-se como um grande mestre e cientista. Nesse curso, a disciplina Química era ministrada pelo professor Rômulo Ciolla e contava com aulas teóricas e práticas, realizadas em laboratório próprio. O professor Aziz Nacib Ab'Saber ministrava Geografia. Integravam ainda o currículo a Geometria Descritiva, Educação Física e Línguas, que tinha como metodologia a leitura e a análise de livros clássicos.

Ainda sobre o curso cientifico, Ubiratan D'Ambrosio lembrou que os professores Leila Cury e Hamílcar Turelli ministravam Português com leitura integral e comentada da obra Os Lusíadas. Em Inglês, o livro-texto era Five Tragedies of Shakespeare; em Francês, clássicos como Madame Bovary; em Espanhol, Don Quijote e poesias de Ruben Darío. Contava também com a disciplina História, ministrada pelo professor Manuel Nunes Dias, considerado um especialista em descobrimentos portugueses. De acordo com Ubiratan D’Ambrosio, aquele nível de ensino veio a contribuir com sua formação: "Era um colégio excepcional. E eu acho que isso foi decisivo na minha formação" (depoimento oral, 2004).

No ano de 1948, D’Ambrosio começou a ministrar aulas particulares para alunos que se preparavam para os concursos públicos e em 1949 fez o curso preparatório para o exame vestibular, simultaneamente ao terceiro ano do curso científico. Esse curso preparatório era dirigido pelo matemático italiano Pompeo di Tullio, que veio para o Brasil logo depois da II Guerra Mundial, e nele constavam conteúdos matemáticos presentes no primeiro ano de faculdade.

\section{UBIRATAN D'AMBROSIO NA FACULDADE}

Em continuidade à sua formação acadêmica, Ubiratan D'Ambrosio fez uma incursão por seu tempo de faculdade. Em 1950, ingressou na Faculdade de Filosofia, Ciências e Letras da Universidade de São Paulo, mais especificamente no Curso de Licenciatura e Bacharelado em Matemática.

Ubiratan D'Ambrosio relembrou professores que teve no primeiro ano da faculdade: Elza Gomide, que ministrou Análise, e Benedito Castrucci, que lecionou Geometria Analítica e Geometria Projetiva. Referiuse a eles nos seguintes termos: "eles eram excelentes professores [...], eu não posso imaginar uma postura de professor que náo seja aquela dos meus professores e, de um jeito ou de outro, todos eles eram assim" (depoimento oral, 2004).

O professor Rômulo Ribeiro Pieroni ministrava as disciplinas Física Geral e Experimental, um curso teórico e prático com aulas realizadas no laboratório. $\mathrm{O}$ professor Fernando Furquim de Almeida era o 
responsável pela disciplina Crítica dos Princípios da Matemática, um tipo de Filosofia da Matemática. Trazendo à memória esse professor, Ubiratan D’Ambrosio salientou:

[...] ele era um professor rígido, mas de uma sensibilidade no contato com os alunos, perfeito. [...] a gente tinha um respeito por ele porque a postura dele era compatível com o que ele exigia. Grande professor! E ele em vez de dar Filosofia da Matemática, focalizou o que gostava, que era a filosofia dos números, então nós tivemos um curso de Teoria dos Números, assim, dos mais pesados que se possa imaginar, em nível bem avançado (depoimento oral, 2004).

Prosseguindo em seu depoimento, Ubiratan D'Ambrosio disse que, nos intervalos das aulas, os alunos ficavam estudando e conversando sobre vários assuntos além da Matemática, como Literatura, por exemplo. Com referência às leituras realizadas, os alunos tinham preferência por aquelas que envolviam peças de teatro, em que cada um assumia um personagem, momentos de grande importância em sua formação.

Nesses intervalos de descanso, Ubiratan D’Ambrosio afirmou que ele e seus colegas também visitavam outros locais que se revestiram de grande significado em sua formação acadêmica, devido à facilidade que tinham para adquirir bons livros e ao incentivo à leitura. Tratavam-se das chamadas Livraria Francesa, Livraria Internacional e distribuidora da Encyclpedia Britannica, locais em que encomendavam os livros comprados em dólar a preços baixos. Essas facilidades muito contribuíram para a construção de sua atual biblioteca.

Ainda em relação ao curso de Matemática na Faculdade de Filosofia, Ubiratan D'Ambrosio mencionou que as aulas, muitas vezes, consistiam em conferências proferidas por matemáticos convidados. Durante essas aulas, os alunos faziam suas anotações em fichas, nas quais complementavam com outras informaçóes obtidas por meio das leituras realizadas. Atualmente essas fichas fazem parte do Arquivo Pessoal Ubiratan D’Ambrosio, do Centro de Documentação do Grupo de Pesquisa em História da Educação Matemática (GHEMAT).

Frequentador assíduo da biblioteca da Faculdade de Filosofia, Ubiratan D’Ambrosio mantinha-se atualizado por meio de leituras de revistas e livros. Despertavam o seu interesse aqueles referentes à História e à Geometria Elementar, sobretudo textos de autoria de Joseph-Louis Lagrange, e à Didática, em especial as obras do professor de Matemática Euclides Roxo e do matemático Félix Klein. O acervo dessa biblioteca ainda possuía obras relativas às teorias da Educação Matemática, dentre as quais destacou o livro "Educação para uma civilização em mudança”, de autoria de W.H. Kilpatrick, o qual teve grande participação em sua formação.

Em 1952, no segundo ano de faculdade do Curso de Matemática, as aulas de Análise eram ministradas pelo professor Omar Catunda. Esse professor ofereceu aos alunos um curso de Geometria Elementar fundamentado em um livro avançado de funçóes de variáveis complexas, de Georges Polya. Esse livro, segundo Ubiratan D’Ambrosio, permitia ao aluno a experimentação baseada na resolução de problemas.

Ainda nesse segundo ano, o professor Fernando Furquim de Almeida ministrou o curso de Teoria dos Números. O professor Cândido da Silva Dias, responsável pela disciplina Complementos de Geometria, baseou-se nos livros do grupo Bourbaki, contemplando conteúdos como Iniciação à Geometria Moderna, Espaços Vetoriais e Álgebra Multilinear. As lembranças de Ubiratan D’Ambrosio remontam aos livros usados nessas aulas:

[...] os livros que a gente usava [...] Complementos de Geometria, que era dada pelo Cândido. A gente tinha um primeiro livro mais elementar, mais fácil, que era do Halmos. Era um livro de Espaços Vetoriais de Dimensáo Finita, recém-publicado nos Estados Unidos. Um livro muito importante. Começava com Espaço Vetorial, mas logo a gente passava para um livro mais avançado, então era só o começo da Teoria dos Números (depoimento oral, 2004). 
Nesse segundo ano, Ubiratan D’Ambrosio apontou que cursaram outras disciplinas, como Mecânica Racional, Geometria Projetiva e ainda Física Geral e Experimental, cujas aulas dividiam-se em teóricas e experimentais.

Também em 1952, Ubiratan D’Ambrosio e seus colegas organizaram uma revista visando contribuir para a atualização dos conhecimentos dos estudantes em uma linguagem mais acessível:

[...] havia uma revista, que é o Boletim da Sociedade de Matemática de São Paulo, muito boa, mas que é só pesquisa. Deveria ter uma revista mais acessível. E aí surgiu a ideia de fazer uma revista, Notas de Matemática e Física. E nossos colegas, todos os alunos [...] achavam que seria importante termos uma revista [...] E foram falar com os professores. Esses disseram: "tem razão, precisa de uma revista. Mas quem faz?", "Nós vamos fazer. Os senhores apoiam?" Ah! Eles apoiaram totalmente (depoimento oral, 2004).

A organização dessa revista demandou discussões e atribuiçóes de açóes entre os alunos. Essa revista foi publicada no ano de 1953, fruto de esforços dos alunos, apoiados pelos professores.

Em 1953, Ubiratan D’Ambrosio fez o terceiro ano do Curso Licenciatura e Bacharelado em Matemática. Em relação às disciplinas desse ano de curso, Mecânica Celeste foi ministrada pelo professor Mário Schemberg; Análise Superior, pelo professor Edson Farah, que adotou um livro do grupo Bourbaki, o qual veio auxiliar Ubiratan na escrita de seu livro de Topologia; Cândido Lima da Silva Dias, responsável pela disciplina Geometria; Omar Catunda, pela Análise Matemática, baseando-se no curso que o matemático italiano Luigi Fantappiè trouxe para o Brasil. Furquim de Almeida ministrou a disciplina Crítica dos Princípios da Matemática, através da qual se deu continuidade ao estudo da Teoria dos Números.

No ano de 1954, Ubiratan D'Ambrosio estava no quarto ano da faculdade. Nesse período, teve três disciplinas: Geometria Elementar, Teoria dos Números e Análise Superior. Ao término desse ano, concluiu o bacharelado. Ele se referiu à importância desse curso em sua carreira profissional: "[...] difícil imaginar alguém nesse mundo que tenha tido um curso melhor [...]. Depois que eu fui para os EUA, conheci muita gente, também na Europa. Mas esse curso foi uma coisa assim, uma coisa fundamental em minha vida" (depoimento oral, 2004).

No quinto ano, na Faculdade de Filosofia, em 1955, Ubiratan D’Ambrosio cursou as disciplinas complementares da licenciatura. Foram ministradas Didática Geral e Psicologia da Criança e do Adolescente, uma disciplina que, a seu ver, foi de grande importância em sua formação docente, pois muito do que se fazia e se discutia nessas aulas refletia uma postura de olhar para a criança, observando o processo de aprendizagem, considerando muito mais o comportamento e as angústias da criança e do adolescente. Segundo suas palavras:

\footnotetext{
Naquele tempo, era muito nova a Psicologia Experimental, focalizando o comportamento da criança, o comportamento do adolescente e, claro, com referência às coisas que tinham algo a ver com a aprendizagem, mas muito pouco. [...] naquela época, a ideia era você fazer uma psicologia experimental e ver os distúrbios que poderiam ter no comportamento da criança e do adolescente. [...] assim, eu tive a minha formação de Educação. Muito pouco de Educaçáo Matemática [...] eram coisas de formação de cultura geral (depoimento oral, 2004).
}

Concluindo essas disciplinas complementares exigidas, Ubiratan foi também habilitado em Licenciatura em Matemática no final desse ano de 1955.

\section{A CARREIRA DOCENTE DE UbirATAN D'AMBrosio}

Ubiratan D'Ambrosio iniciou sua carreira docente no Colégio Visconde de Porto Seguro. Era o ano de 1953 e ele, embora ainda aluno do curso de Licenciatura, já portava um registro provisório para exercer o magistério. Ele disse que, nesse colégio, procurou ensinar, no curso 
ginasial, uma Matemática nova, mais experimental, em harmonia com o que estava aprendendo na faculdade.

Esse Colégio submetia-se ao controle do Ministério da Educação, realizado por inspetores federais que visitavam as escolas; eles eram de diferentes áreas, coordenados pela Inspetoria Seccional de São Paulo. A educadora Marina Cintra era responsável por essa Seccional e realizava reuniōes, simpósios e seminários nos quais se discutiam questôes da educação e da Educação Matemática. Ocasionalmente, nesses encontros, Ubiratan D'Ambrosio expunha suas ideias fundamentado nas leituras que fazia.

No ano de 1956, Ubiratan D'Ambrosio iniciou sua carreira como professor universitário na Pontifícia Universidade Católica de Campinas, onde ministrou aulas na Licenciatura, assumindo a cadeira de professor de Análise Matemática. Nessa universidade, organizou o Curso de Matemática, que tornou significativa a sua participação na Educação Matemática. Nesse curso, foi abordada a importância da Psicologia da Aprendizagem, Psicologia da Criança e do Adolescente.

No ano de 1957, Ubiratan D'Ambrosio e seu pai ministraram um curso no âmbito da Campanha de Aperfeiçoamento e Difusão do Ensino Secundário (CADES), na cidade de Florianópolis, no estado de Santa Catarina, com duração de dois meses. Tratavase de uma iniciativa do governo para a promoção de uma ampla reforma do sistema educacional brasileiro. A CADES promovia cursos para professores leigos e padres que já atuavam como professores de Matemática, mas que não possuíam certificados de Licenciatura, legalizando sua situação funcional.

Ubiratan D'Ambrosio falou sobre essa licenciatura de dois meses em que havia duas disciplinas, uma de Didática e outra de conteúdo matemático. Aos alunos, a CADES oferecia uma coleção de livros da área de interesse dos participantes. Em meio a esses livros encontravam-se volumes de Matemática moderna e livros-texto diversificados. Esse curso tinha como função mostrar aos professores novas possibilidades de ensino.

Com base nessa sua participaçáo no curso da CADES, Ubiratan D’Ambrosio elaborou um programa com sugestões para o ensino de Matemática, que foi apresentado no ano de 1957, no Primeiro Encontro de Mestres realizado na cidade de São Paulo e no II Congresso Nacional de Ensino de Matemática, na cidade de Porto Alegre, no estado do Rio Grande do Sul. Assim, referiu-se à escrita desse artigo, quando se inspirou na obra L'Enseignement des Mathématiques publicado em 1955:

Era o espírito da "Matemática Moderna", que eu havia lido em alguns livros e artigos, e era o que eu achava, conhecendo bem Álgebra, pois estudei muito isso no curso da Faculdade de Filosofia, Piaget junto com Lichnerowicz, com Dieudonné, com alguns outros, em um livro com fins de Educação Matemática. Aquilo que estava na minha cabeça, de repente eu me via fazendo esse tipo de coisa e eu resolvi fazer um artigo sobre isso, e esse é o trabalho de 1957 (depoimento oral, 2004).

Segundo Ubiratan D'Ambrosio, nesse mesmo período, Jean Piaget pesquisava as estruturas mentais da criança, instaurando um fecundo diálogo com profissionais de várias áreas: matemáticos, psicólogos e pedagogos. Relativamente ao artigo apresentado no II Congresso de Ensino de Matemática em 1957, D'Ambrosio relatou que se emocionou quando soube que seu artigo fora aceito no evento: "[...] o trabalho era distribuído aos participantes e alguém avaliava a aprovação [...] e foi aprovado. Era a proposta que eu queria” (depoimento oral, 2004). Nesse artigo, defendeu a necessidade de modernização do ensino de Matemática.

Para Ubiratan, suas colocações não encontraram eco entre os professores nesse evento, pois, naquela época, era "jovem, recém-formado e possuidor de pouca experiência”. Ele relembrou: "Àquelas inquietações que apresentei em 1957, ninguém deu importância” (depoimento oral, 2004). Entretanto, em 1962, os 
professores defensores das propostas reformistas da Matemática Moderna apresentaram quase que as mesmas ideias sugeridas por ele em 1957, o que valeu um desabafo:

\begin{abstract}
Pouquíssimo tempo depois, eles vieram a fazer a mesma coisa. Melhor dizendo, não é a mesma coisa, era menos do que eu estava propondo. As ideias deles eram mais moderadas, mais tímidas. Eu não estava lá muito de acordo com o que eles estavam propondo, muito estruturado, muito formal e a minha ideia era fazer uma matemática mais instrumental (depoimento oral, 2004).
\end{abstract}

Como professor, Ubiratan D'Ambrosio, no ano de 1957, ministrou aulas de Física em um curso Clássico no Colégio Nossa Senhora de Sion. Rememorou que fez uso de uma metodologia de ensino diferenciada daquela até então utilizada.

Nesse mesmo ano, lançou o livro "Matemática Financeira” juntamente com seu pai Nicolau D’Ambrosio.

[...] minha colaboração no livro foi dizer: "Bom, não basta isso! Eles têm que olhar para o que está acontecendo de novo, de moderno aqui!" E esse livro, uma parte dele, era Matemática Financeira. Eu disse: "hoje temos Cálculo Integral". Por isso, eu dava Cálculo Integral na Matemática Financeira. E programação linear, o que é isso? Estava nascendo. Eu dizia: "náo, o pessoal de finanças [...] tem que entender o que é programação linear". E ela entrou no livro, eu acho que foi o primeiro livro que se publicou aqui no Brasil. Livro desse nível, que introduz e fala de programação linear (depoimento oral, 2004).

No ano seguinte, 1958, Ubiratan D'Ambrosio casou-se com Maria José e foi lecionar na Escola de Engenharia da Universidade de São Paulo, situada na cidade de São Carlos, no estado de São Paulo, onde foi assistente do professor Jaurès Cecconi. Acabou por se tornar orientando de doutorado desse professor, quando trabalhou com a Teoria dos corpos de classes, consolidada, pelo matemático francês Claude Chevalley, como uma teoria matemática importante nos anos 1930.

Como estava interessado nesse tema e sabendo que Chevalley fora convidado para dar um curso no Japão, Ubiratan D’Ambrosio escreveu para a Sociedade
Japonesa de Matemática interessado em obter uma cópia do referido curso que, posteriormente, o matemático Yukiosi Kawada encaminhou-lhe por carta.

Tempos depois, Kawada foi convidado para ministrar alguns cursos no Instituto de Matemática e Física, na Universidade Federal da Bahia. Ubiratan D’Ambrosio passou um mês naquele Instituto na qualidade de professor visitante, ocasião em que proferiu um curso sobre Teoria das Distribuiçóes. Por intermédio de Kawada, D’Ambrosio conheceu o matemático Shoichi Yanaga, o qual se mostrou interessado em Educação Matemática e foi eleito presidente do International Congress on Mathematical Education (ICME). Para Ubiratan D'Ambrosio:

$$
\begin{aligned}
& \text { [...] os matemáticos muito altos não desprezam [a } \\
& \text { Educaçáo Matemática]. Esses que desprezam são } \\
& \text { matemáticos, no fundo, de menor categoria. Então } \\
& \text { é o tipo de recurso que eles têm para se proteger. } \\
& \text { Mas [...] os grandes matemáticos reconhecem } \\
& \text { que a Educação Matemática é importante, } \\
& \text { reconhecem que eles devem se interessar } \\
& \text { (depoimento oral, 2004). }
\end{aligned}
$$

Em 1960, como professor de Álgebra Superior e de Análise Superior no Curso de Licenciatura em Matemática da UNESP, na cidade de Rio Claro, estado de São Paulo, Ubiratan D’Ambrosio soube que o professor Caleb Gattegno visitaria a Argentina. Assim, convidou-o para fazer uma palestra na Faculdade de Filosofia dessa universidade. Gattegno aceitou o convite e fez uma apresentação sobre números em cores, defendendo uma proposta de renovação do ensino de Matemática Moderna com base na Psicologia.

No ano de 1961, Ubiratan D’Ambrosio publicou o artigo A álgebra moderna e a Escola Secundária na revista Atualidades Pedagógicas, destinado aos professores da rede pública de ensino. Sua preocupação era estreitar a distância existente entre os assuntos discutidos nas pesquisas acadêmicas e na escola básica, pois os professores de Matemática "estavam sempre na fronteira da pesquisa matemática" e ele "ficava inconformado de ver todas 
essas coisas não chegarem à escola" (depoimento oral, 2004). Nesse artigo, Ubiratan D’Ambrosio mencionou o matemático Alfred North Whitehead, que defendia que o professor deveria considerar que a compreensão da criança, em relação ao mundo que a cerca, dá-se de forma global. Concordando com essa afirmação, alertou que "não estamos levando em conta isso. Precisamos mudar! Não vamos continuar na mesmice!" (depoimento oral, 2004). Ainda em 1961, intermediou a visita do professor George Springer, da Universidade de Kansas, para a UNESP, na cidade de Rio Claro/SP, o qual proferiu uma conferência abordando o Movimento da Matemática Moderna que já ocorria em outros países.

Em 1963, Ubiratan D’Ambrosio tomou conhecimento de que a National Aeronautics and Space Administration (NASA) estava recrutando pesquisadores no congresso Space Mathematics. Ele se candidatou e foi aprovado como pesquisador matemático da NASA para atuar no Summer Institute on Space Mathematics, com bolsa de estudos da American Mathematics Society. Antes de se mudar para os Estados Unidos, em 08 de dezembro de 1963, na Escola de Engenharia de São Carlos da Universidade de São Paulo, Ubiratan D'Ambrosio defendeu sua tese de doutorado Superfícies generalizadas e conjuntos de perimetro finito, sob a orientação do Dr. Jaurès P. Cecconi. Fizeram parte da banca de defesa de sua tese os professores Gilberto Loibel, Nelson Onuchic, Domingos Pisanelli, Abrão de Moraes e Cândido Lima da Silva Dias, todos da USP.

Terminado o doutorado, em 1964, Ubiratan D’Ambrosio foi para os Estados Unidos, acompanhado de sua esposa Maria José e dos dois filhos, atendendo ao convite feito pelo professor Wendell H. Fleming, especialista em cálculo das variaçóes, em Nova Iorque. Ubiratan D'Ambrosio assumiu como pesquisador associado na Brown University, em Rhode Island, Estados Unidos, junto ao matemático italiano Ennio De Giorgi. Naquela época, o governo americano criou um mestrado específico para os professores do ensino secundário, denominado Master of Arts in Teaching. Nesse programa de Pós-graduação, os alunos eram matemáticos que possuíam interesse no ensino de Matemática no curso secundário. Ubiratan D’Ambrosio ministrou aulas de Geometria e Álgebra.

Em 1965, Ubiratan D’Ambrosio ministrou cursos avançados de Topologia a convite da State University of New York at Buffalo. Em janeiro de 1966, Ubiratan D'Ambrosio foi convidado pelo professor Fleming para dar aulas como professor associado na University of Rhode Island, para onde se mudou com a família, ficando por dois anos.

Em junho de 1968, ele retornou a Buffalo coma função de coordenador da Pós-graduação em Matemática Pura. Foi um momento de defesa de tese de seu primeiro orientando T. K. Puttaswamy, intitulada The solutions in the large of a certain class of third order differential equations of W. B. Ford's type. Nessa universidade, iniciou sua formação transdisciplinar participando de grupos de outras áreas de conhecimento e ainda de um movimento sobre limites de cotas para alunos americanos negros.

Em 1972, recebeu um convite para trabalhar na Universidade Estadual de Campinas (Unicamp), no estado de São Paulo, e decidiu voltar ao Brasil, indo morar na cidade de Campinas/SP. Ubiratan D'Ambrosio salientou que a Unicamp o recebeu muito bem nesse seu regresso dos Estados Unidos, quando assumiu o cargo de Diretor do Instituto de Matemática, Estatística e Ciência da Computação.

Naquela época, estava ocorrendo uma reforma de Educação em Matemática e Ciências em todas as Américas. Na Unicamp, um grupo de educadores brasileiros defendia o ensino modular, já praticado em universidades americanas. Nessa direção, foi criado o Projeto Multinacional para a Melhoria do Ensino de Ciências (PROMULMEC), em convênio com a Organização dos Estados Americanos (OEA) e apoio do 
Programa para Melhoria do Ensino (PREMEM). No âmbito desse programa foi criado o Curso de Mestrado em Ensino de Ciências e Matemática nessa Instituição, do qual Ubiratan D'Ambrosio foi coordenador (D'AMBROSIO, 1984).

Com duração de dois anos, esse mestrado recebia alunos latino-americanos com bolsa oferecida pela OEA e contou com visitas de pesquisadores como Hassler Withney e Guy Brousseau. Em uma primeira etapa, os alunos faziam o projeto de pesquisa e as disciplinas sensibilizadoras na Unicamp:

[...] os projetos de pesquisa têm que estar ligados às coisas que motivam o aluno, para que o aluno se envolva. Isso é importante. Por isso que no curso da OEA, no mestrado, os alunos passavam mais ou menos dois meses cursando disciplinas sensibilizadoras, onde discutiam, liam jornais, pensavam sobre o país de origem, sobre a família (depoimento oral, 2004).

$\mathrm{Na}$ segunda etapa, dava-se o desenvolvimento da pesquisa de mestrado realizada no país de origem dos alunos, privilegiando a realidade vivida em suas localidades. Ao final dessa fase, eles retornavam ao Brasil para a conclusão do trabalho. $\mathrm{Na}$ opinião de Ubiratan D’Ambrosio, esse programa rompeu muitas barreiras,

[...] foi uma maravilha! Não tem outra palavra. [...] essa é a minha melhor experiência de ensino de pósgraduação, essa da OEA. E os efeitos ficam. Mesmo que não haja outro curso igual. Em várias partes do Brasil e mesmo da América Latina tem [...] gente que brilhou por aí. Vários professores titulares, também reitor. Esse curso valeu! (depoimento oral, 2004).

Ficou no cargo de Diretor do Instituto da UNICAMP até finais de 1980, quando retornou aos Estados Unidos, assumindo como chefe da Unidade de Melhoramento de Sistemas Educativos da OEA, coordenando todos os programas de Educação da América Latina.

Em 1982, retornou ao Brasil, para assumir como Pró-reitor de Desenvolvimento Universitário da Universidade de Campinas, cargo que exerceu até 1990. No período de 1990 a 1993, ficou como membro do Conselho Científico do Núcleo Interdisciplinar de Pesquisas LUME/Laboratório de Movimento e Expressão, do Instituto de Artes dessa Universidade.

Ubiratan D'Ambrosio começou a participar das reuniôes anuais da Pugwash Conferences on science and Word Affairs, a partir de 1978. Nessas reunióes, são discutidos temas relacionados aos problemas nucleares e a paz em geral. Os membros dessa conferência são eleitos pelos participantes ativos dessa organização; Ubiratan D’Ambrosio foi eleito em 1987 e reeleito em 1992.

Em 1995, em reconhecimento pelo serviço realizado em nome da paz mundial, a Fundação Nobel da Paz concedeu à Pugwash Conferences on science and Word Affairs e ao professor Joseph Rotblat, então presidente dessa mesma organização o prêmio Nobel da Paz, (D’AMBROSIO, depoimento, apud CHASSOT; KNIJNIK,1997).

A formação pessoal e profissional de Ubiratan D'Ambrosio levou-o a criar o Programa de Etnomatemática. Para D’Ambrosio (2014), pode-se explorar a Etnomatemática como um programa de investigação, servindo-se da observação de práticas de diferentes grupos culturais. Pode-se igualmente explorar a história da matemática, tomando por base a análise de narrativas de diferentes atores no processo de criação de matemática. Deve-se reconhecer naquele conhecimento construído a condição humana, atentando para a Matemática dos não matemáticos. Trata-se, portanto, de:

[...] um programa de investigação sobre a geração, organizaçáo individual e social, transmissão e difusão do conhecimento. Esses objetivos incluem as disciplinas tradicionais das ciências da cognição (geração de conhecimento), da epistemologia (organizaçáo do conhecimento) e de história, sociologia, política e educação (transmissão e difusão do conhecimento). [...] o Programa de Etnomatemática é motivado pelo compromisso de cumprir maiores responsabilidades de um educador, que está preparando novas geraçóes para criar uma nova ordem econômica e política que rejeita a desigualdade, a arrogância e o fanatismo (D’AMBROSIO, 2014, p. 100). 
O aspecto pedagógico da Etnomatemática permite notar que a relação entre a Etnomatemática e o ensino da matemática é natural, pois esse ensino busca preparar jovens e adultos para exercerem, com criatividade, uma cidadania crítica em sociedade. Assim, a Etnomatemática propõe uma pedagogia viva e dinâmica que responda a novos estímulos ambientais, sociais e culturais. Diz respeito à "vida cotidiana, trabalho e diversão, literatura, revistas e notícias, jornais, rádio e televisão, filmes etc.", os quais possuem componentes matemáticos relevantes (D’Ambrosio, 2014, p.107). Com a veiculação das ideias desse Programa, em 1985, foi oficializado o Grupo de Estudo Internacional sobre Etnomatemática - ISGEm.

Em 1988, Ubiratan D’Ambrosio tornou-se professor do Programa de Pós-graduação em Educação Matemática da UNESP e, a partir de 1997, professor no Programa de Pós-graduação em História da Ciência da Pontifícia Universidade Católica de São Paulo. Desde o ano de 2000 é professor do Programa de Pós-graduação em Educação da USP e a partir de 2009 tornou-se professor do Programa de Pós-graduação em Educação Matemática da Universidade Anhanguera de São Paulo.

No ano de 2005, Ubiratan D'Ambrosio recebeu a maior condecoração mundial na área da Educação Matemática, a Medalha Felix Klein, pela International Comission on Mathematics Instruction (ICMI). Essa premiação se deu pelo reconhecimento da comunidade científica às suas relevantes contribuições no campo da Educação Matemática, amplamente disseminadas por meio de publicações e conferências realizadas em congressos pelos mais diversos países (SBEM, 2006). Essa distinção deve-se ao reconhecimento do papel que Ubiratan tem desenvolvido:

[...] na instrução da Matemática como um campo de pesquisa e no desenvolvimento em todo o mundo, sobretudo em América Latina. Reconhece também seu papel abrindo caminho no desenvolvimento das perspectivas da pesquisa sensíveis às características dos contextos sociais, culturais e históricos em que o ensino e a aprendizagem da Matemática ocorrem, bem como sua insistência em fornecer a instrução da Matemática de qualidade a todos e não apenas a um segmento privilegiado da sociedade (ARTIGUE apud BARBIERI, 2006).

Ubiratan D'Ambrosio continua contribuindo para as pesquisas na área da Educação Matemática, orientando alunos de diversas universidades do Brasil e do exterior. Desse modo, a história de vida desse professor reflete os desafios que sempre enfrentou, desvelados nas marcas deixadas pelas diversas etapas de sua formação.

\section{CONSIDERAÇÓES FINAIS}

A história de vida do professor, pesquisador e educador Ubiratan D'Ambrosio é reveladora de aspectos inerentes à Educação, especialmente à Educação Matemática, com a qual está permanentemente vinculado, conforme atestam suas experiências educacionais. A partir dos depoimentos de D'Ambrosio, pode-se perceber que sua vida foi dedicada à formação dos alunos, em todos os níveis de ensino, e à formação de professores, sempre preocupado com a Matemática e outras áreas do saber.

Ubiratan D’Ambrosio está sempre fazendo reflexôes sobre a própria ação educacional e defende princípios, valores culturais e metodologias de ensino que contribuam para a renovação do ensino. De acordo com Nóvoa (1992, p. 07), essa realidade contribui para a produção de um conhecimento que reflete as realidades educativas e o cotidiano dos professores, pois "não é possível separar o eu pessoal do eu profissional, sobretudo em uma profissão fortemente impregnada de valores e de ideais e muito exigente do ponto de vista da dedicação e da relação humana”.

A história de vida do professor Ubiratan D’Ambrosio pode, dessa forma, contribuir para uma reflexão sobre a Educação. Suas ações resultam de uma mistura de aspiraçôes, experiências e resultados obtidos que se firmaram em gestos e hábitos com os quais se identifica como docente. Pode auxiliar, portanto, na 
apropriação de diferentes processos de ensino e de aprendizagem e apreensão do cotidiano escolar e revela o necessário e eterno começar da pesquisa.

\section{The Many aspects OF Brazilian EDUCATION: THE PERFORMANCE OF THE TEACHER UBIRATAN D'Ambrosio}

\section{Abstract}

This article discusses the contributions of the teacher and researcher Ubiratan D'Ambrosio to the Brazilian education. The theoretical framework considers the impossibility of detaching the personal being from the professional being. In this way, this work goes through different and successive stages of his life, from his childhood to the present day. All data have been obtained from interviews with Ubiratan D'Ambrosio and information collected in documents belonging to his personal archive. The construction of the life story of this educator and researcher is fruitful for the understanding of the trajectories of teacher training and it contributes to the understanding of the universe of education.

Keywords: Brazilian education. Life story. Teacher formation.

\section{Múltiples Aspectos de la eduCación BRASILEÑA: LA ACTUACIÓN DEL PROFESOR UBIRATAN D'AMBrosio}

\section{Resumen}

Este artículo discute las contribuciones del profesor e investigador Ubiratan D'Ambrosio a la educación brasileña. El marco teórico considera la imposibilidad de separar el ser personal del profesional. De esta manera, este trabajo pasa por diferentes y sucesivas etapas de su vida, desde su infancia hasta la actualidad. Todos los datos se obtuvieron de entrevistas realizadas con Ubiratan D’Ambrosio y de la información recopilada en documentos pertenecientes a su colección personal. La construcción de la historia de vida de este educador e investigador es fructífera para la comprensión de las trayectorias de formación del docente y contribuye a la comprensión del universo de la educación.

Palabras clave: Educación brasileña. Historia de vida. Formación docente.

\section{REFERÊNCIAS}

BARBIERI, J. Ubiratan D'Ambrosio recebe prêmio da ICMI. UNICAMP. 2016. Disponível em: < http://www.unicamp. br/unicamp/noticias/ubiratan-dambrosio-recebe-prêmio-daicmi >. Acesso em: 4 dez. 2017.

CHASSOT, A.; KNIJNIK, G. Conversando com Ubiratan D’Ambrosio. Epsteme. Porto Alegre. v. 2, n. 4, 1997, p. $96-$ 110.

D'AMBROSIO, U. Entrevistas concedidas à Aparecida Rodrigues Silva Duarte e Rosimeire Aparecida Soares Borges. Pontifícia Universidade Católica de São Paulo, São Paulo. 2004.

D’AMBROSIO, U. (Coord.). O ensino de ciências e matemática na América Latina. Campinas: Papirus. 1984.

D'AMBROSIO, U. Las bases conceptuales del Programa Etnomatemática. Revista Latinoamericana de Etnomatemática, Revista Latinoamericana de Etnomatemática. v. 7, n. 2, 2014. p. 100-107.

FREITAS, S. M. História oral: possibilidades e procedimentos. São Paulo: Humanitas / FELCH/USP: Imprensa Oficial do Estado, 2000.

NÓVOA, A. Os professores e as histórias da sua vida. In: Nóvoa, A. (Org.). Vidas de professores. Porto: Porto Editora, 2000. p. 11-30. 
SBEM. ICMI outorga a Ubiratan D'Ambrosio a Medalha Felix Klein. Boletim Eletrônico da Sociedade Brasileira de Educação Matemática. Edição Especial, 2, Número Especial, 2006, p.1- 4 .

Enviado em 15 de março de 2018. Aprovado em 20 de junho de 2018. 